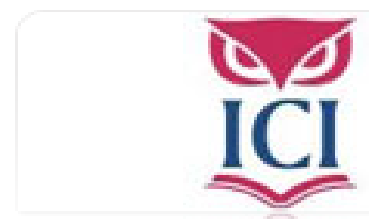

IUS. Revista del Instituto de Ciencias Jurídicas de Puebla A.C.

ISSN: 1870-2147

revista.ius@hotmail.com

Instituto de Ciencias Jurídicas de Puebla A. C.

México

Flores Salgado, Lucerito Ludmila

Las personas discapacitadas como grupo vulnerable a la luz de la Constitución mexicana

IUS. Revista del Instituto de Ciencias Jurídicas de Puebla A.C., vol. IV, núm. 26, 2010, pp. 113-125

Instituto de Ciencias Jurídicas de Puebla A. C.

Puebla, México 


\section{Las personas discapacitadas como grupo vulnerable a la luz de la Constitución mexicana*} Disabled persons as a vulnerable group in the light of the Mexican Constitution

\section{Lucerito Ludmila Flores Salgado**}

\section{RESUMEN}

El tema de las personas discapacitadas es todo un reto, ya que desde el primer núcleo de la sociedad, que es la familia, la mayoria de ellas enfrentan los primeros problemas de aceptación, maltrato y total dependencia de la familia, posteriormente la lucha es acomodarse en la sociedad, misma que los discrimina y margina, tratándolos como personas "defectuosas". El reto es propiciar una sociedad integrante, que les permita el ejercicio de sus derechos dentro de un marco jurídico justo, que permita una verdadera igualdad y hacer efectivo el principio de la no discriminación.

PALABRAS CLAVE: Grupos vulnerables, personas discapacitadas, derechos humanos, discapacidad, derechos de las personas discapacitadas.

\begin{abstract}
The topic of the disabled people is a challenge, and that from the first unit of society is the family, most of these people faced the first problems of acceptance, abuse and total dependence on family then the fight is accommodated in society, it discriminates and marginalizes the people treating them as "defective." The challenge is to foster a society member, to enable them to exercise their rights within a fair legal framework that allows for true equality and to implement the principle of non-discrimination.
\end{abstract}

KEY WORDS: Vulnerable groups, disabled persons, human rights, disability rights, disabled persons.

\footnotetext{
* Recibido: 9 de agosto de 2010. Aceptado: 31 de agosto de 2010.

* Profesora-investigadora de tiempo completo en la Facultad de Derecho y Ciencias Sociales de la BuAP. (lucerito_flores@hotmail.com).
} 


\section{Sumario}

1. Introducción

2. Los grupos vulnerables en México

3. Los derechos humanos en el siglo XXI

4. El concepto de discapacidad

5. Marco jurídico regulatorio de los derechos de las personas con discapacidad

6. Conclusión

7. Bibliografía

\section{Introducción}

En el presente siglo uno de los problemas latentes que preocupan al orden mundial son las personas discapacitadas, mismas que, según el Dossier Informativo sobre las Normas Uniformes de las Naciones Unidas sobre la lgualdad de Oportunidades para las Personas con Discapacidad, establece que 100 millones de personas padecen minusvalía causada por la mal nutrición, 20 millones de personas necesitan sillas de ruedas, y que en algunos países el promedio de vida del 90\% de los niños discapacitados es de 20 años, ${ }^{1}$ esto significa que a pesar de que existan normas tanto nacionales como internacionales que protegen a dichas personas, éstas sufren de discriminación, entendiéndose ésta como:

[...] toda distinción, exclusión o restricción, que basada en el origen étnico o nacional, el sexo, la edad, la discapacidad, la condición social o económica, las condiciones de salud, el embarazo, la lengua, la religión, las opiniones, las preferencias sexuales, el estado civil o cualquier otra, tenga por efecto impedir o anular el reconocimiento o el ejercicio de los derechos fundamentales y la igualdad real de oportunidades. ${ }^{2}$

Por lo que dicho sector de la población forma una parte muy importante de los llamados grupos vulnerables del mundo.

La discapacidad, como tal, es una necesidad jurídica que trasciende todos los ámbitos de la vida humana, es un derecho humano considerado desde la primera generación, con los llamados derechos personales y de la dignidad humana, hasta la actual cuarta generación, que vela por la protección específica de los derechos de los discapacitados; la preocupación por la protección de tales derechos es tal que ha llegado hasta la comunidad internacional, firmándose tratados y convenios para la protección de los mismos. Constitucionalmente, podemos

\footnotetext{
Ortega Villalobos, Joel, México, 2000.

2 Fracción vil de la Ley Federal para Personas con Discapacidad.
} 
considerar al derecho de las personas con discapacidad como un derecho mixto, pues su regulación la podemos encontrar desde la parte dogmática de la Constitución, considerándose todas las garantías de las que son sujetos, como las de igualdad, libertad, propiedad y seguridad jurídica, hasta la parte orgánica, que es la parte social de la Constitución, tratándose el aspecto laboral al que también tienen derecho, establecido en el artículo 123 constitucional.

Es importante señalar que aunque en nuestro país existen leyes que protegen sus derechos, aún existe la discriminación en el acceso a servicios, en programas prioritarios y en el ámbito laboral, se debe tener como prioridad crear campañas de educación vial, cortesía urbana y respeto hacia las personas con capacidades diferentes en su tránsito por la vía pública y lugares de acceso público, funcionalidad en los medios de transporte público, terminando con todos aquellos obstáculos que dificultan, entorpecen o impiden a las personas con discapacidad, su libre desplazamiento en lugares públicos o privados, exteriores, interiores o el uso de los servicios comunitarios.

\section{Los grupos vulnerables en México}

Los grupos vulnerables son conjuntos de personas que se encuentran en un estado de indefensión, es decir, que tienen sus garantías, derechos y libertades vigentes, pero que en la práctica no se les reconoce, y están expuestas a la violación de sus derechos; se encuentran en estado de vulnerabilidad por su género, edad, preferencias sexuales, discapacidad, origen étnico, nivel económico, son marginados, lo cual los pone en desventaja con las demás personas integrantes de una comunidad social.

La responsabilidad del Estado es hacer que la ley se ponga en práctica, ya que sus derechos son violados constantemente, porque no los conocen, por ignorancia o falta de recursos para hacerlos valer ante los órganos jurisdiccionales, es aquí donde entra el papel de los protectores de los derechos humanos.

En México la vulnerabilidad de ciertos grupos sociales es provocada por la falta de trabajo, o trabajos mal remunerados, enfermedades causadas por el estrés y la desnutrición, la marginación social y la polarización global, identificándose como grupos vulnerables:

a) Los grupos étnicos, pues se reconoce a México como una nación pluricultural, es decir, que existen tantas culturas como pueblos indígenas.

b) Las personas discapacitadas son las que padecen temporal o permanentemente una disminución en sus facultades físicas, mentales o sensoria- 
les. Tienen derecho a una vida plena y digna, y se les debe garantizar la igualdad de oportunidades mediante la eliminación de todas las barreras físicas, sociales o culturales que las excluyen de su plena participación en la sociedad. Deben de considerarse como derechos de las personas discapacitadas el derecho a la protección de su salud, derecho al trabajo, derechos políticos, derecho urbanístico (instalaciones urbanísticas y arquitectónicas adecuadas, que les permitan desarrollar sus actividades), derecho a la cultura y deporte, derecho a la protección del consumidor, derechos fiscales.

c) Personas con sIDA. En el presente siglo se ha acentuado la discriminación en contra de las personas que tiene el Virus de la Inmunodeficiencia Humana $(\mathrm{VIH})$ o el Síndrome de Inmunodeficiencia Adquirida (SIDA).

d) Los niños y niñas, como menores con incapacidad, así considerados por el Código Civil, están siempre susceptibles al abuso de sus derechos y de su físico.

e) Las mujeres siguen día a día con la lucha constante de alcanzar la protección plena de sus derechos, principalmente el derecho de igualdad.

f) Derechos de las personas de la tercera edad, que como incapaces muchas de ellas tienden a solicitar al Estado la protección en materia de seguridad social, procuración y administración de justicia.

\section{Los derechos humanos en el siglo $\mathrm{xxl}$}

El Diccionario jurídico mexicano define a los derechos humanos como el conjunto de facultades, prerrogativas, libertades y pretensiones de carácter civil, político, económico, social y cultural, incluidos los recursos y mecanismos de garantía de todas ellas, que se reconocen al ser humano considerado individual y colectivamente. ${ }^{3}$

En México se les llamó derechos del hombre en 1857, y es la Constitución Política de los Estados Unidos Mexicanos, promulgada el 5 de febrero de 1917, la que marca una etapa de la evolución de los derechos humanos, pues abarca 34 artículos de los 136 que conforman la Constitución, comprendiendo tres grupos de derechos: los derechos civiles: artículos 1, 2 y 4 al 24. Los derechos políticos: artículo 35. Los derechos económicos, sociales y culturales: artículos 3, 27, 28 y 123, además del juicio de amparo establecido en los artículos 103 fracción 1, y 107.

3 Rodriguez y Rodriguez, Jesús, Diccionario jurídico mexicano, 6a. ed., Porrúa-unam, Instituto de Investigaciones Juridicas, p. 1063. 
Los derechos de primera generación defendían a los ciudadanos frente al poder del Estado, son los que inciden sobre la expresión de libertad, derechos económicos, sociales, culturales, a la dignidad de la persona y su autonomía, derecho a su integridad física; los derechos de segunda generación se incorporan a partir de una tradición de pensamiento humanista y socialista, son de naturaleza económica y social, e inciden sobre la expresión de igualdad de los individuos, como el derecho a la educación, al trabajo, y a una salud garantizada por el Estado.

Los llamados derechos de la solidaridad constituyen una tercera generación que se concretiza en la segunda mitad del siglo xx. Se crean declaraciones sectoriales que protegen los derechos de colectivos discriminados, grupos de edad, minorías étnicas o religiosas, países del tercer mundo, que son afectados por alguna de las múltiples manifestaciones que cobra la discriminación económico-social, como son el respeto y la conservación de la diversidad cultural, la protección del medio ambiente, la conservación del patrimonio cultural de la humanidad. ${ }^{4}$

Los derechos humanos de cuarta generación son resultado de las necesidades humanas, donde estas exigencias obligan a desarrollar nuevos derechos que garanticen el acceso universal a formas más avanzadas de ciudadanía y civilidad, de libertad y de calidad de vida, mismos que incluyen, entre otros derechos, a la paz y a una justicia internacional, la limitación del derecho a la inmunidad diplomática para determinados delitos, derecho a crear un tribunal internacional que actúe de oficio en los casos de genocidio y crimenes contra la humanidad, desarrollo sostenible que permita preservar el medio ambiente natural, derecho a un entorno multicultural que supere el concepto de tolerancia sexual, las nuevas formas de industrialización y métodos de trabajo, que entraría bajo el rublo de la llamada flexibilización laboral, el uso y establecimiento de nuevas tecnologías como la "inteligencia artificial", los nuevos medios de comunicación masiva (Internet) y la reivindicación de los derechos de 1a., 2a. y 3a. generación en el entorno del ciberespacio y la protección de los derechos de las personas discapacitadas, este último es base de dicho estudio.

El tema de los derechos humanos es recurrente en la historia de la humanidad porque está estrechamente ligado con la dignidad humana; tuvo un gran impulso hace poco más de dos siglos con las declaraciones norteamericanas y francesas, pero es especialmente después de la Segunda Guerra Mundial, y en estas últimas décadas, cuando se han convertido en una de las grandes preocupaciones a nivel internacional. ${ }^{5}$ La crisis financiera que actualmente está

\footnotetext{
${ }^{4}$ Para una mayor ejemplificación de los derechos humanos véase www.cndh.org.mx/losdh.htm.

${ }^{5}$ Carpizo, Jorge, "Los derechos humanos", en Soberanes, José Luis (comp.), Tendencias actuales del derecho, 2a. ed., en http://www.bibliojuridica.org/libros/3/1376/27.pdf.
} 
atravesando el mundo ha dejado a un lado a los derechos humanos, provocando un deterioro de los mismos derechos y libertades, además un recrudecimiento de todo tipo de conflictos, ya que los gobiernos se han concentrado más en la resolución de los problemas económicos que en garantizar los acuerdos internacionales en materia de derechos humanos. Según un reporte de la ONG, la crisis no sólo consiste en escasez de comida, empleo, agua o vivienda, sino también es privación, discriminación y aumento de la desigualdad, la xenofobia, ${ }^{6}$ el racismo, la violencia y la represión. Otros daños colaterales de la crisis económica han sido una mayor discriminación y violencia contra las mujeres, y una política de inmigración más restrictiva para frenar la inmigración ilegal y la persecución de los activistas de derechos humanos. ${ }^{7}$

La defensa o la protección de los derechos humanos tiene la función de contribuir al desarrollo integral de la persona, delimitar, para todas las personas, un área de autonomía dentro de la cual puedan actuar libremente, protegidas contra los abusos de autoridades, servidores públicos y de particulares, establecer límites a las actuaciones de todos los servidores públicos, sin importar su nivel jerárquico o institución gubernamental, sea federal, estatal o municipal, siempre con el fin de prevenir los abusos de poder, negligencia o simple desconocimiento de la función, y crear canales y mecanismos de participación que faciliten a todas las personas tomar parte activa en el manejo de los asuntos públicos y en la adopción de las decisiones comunitarias.

El derecho a la salud, a la educación, a la vivienda, a la alimentación, en general, a vivir una vida digna, son presupuestos esenciales para el desarrollo del ser humano, y deben ser garantizados por todo Estado que se imponga como meta la plena satisfacción de sus miembros. De este modo, y mediante la adopción de políticas públicas encaminadas a proveer a los más necesitados, cuando menos las condiciones de vida mínimas, resultaría viable comenzar a borrar las diferencias sociales y lograr la reinserción del amplio sector de la población que se encuentra actualmente excluido.

En cuanto a recomendaciones concretas, Amnistía Internacional (Al) exhorta a 118 Estados Unidos a reconocer los derechos laborales de los ciudadanos, a la Unión Europea (UE) a proteger a los refugiados, reconocer los derechos de las personas con discapacidades y potenciar la lucha contra el racismo y la xenofobia, y a

\footnotetext{
${ }_{6}^{6}$ Odio u horror ante los extranjeros o lo extranjero, en Gran diccionario enciclopédico visual, Colombia, Programa Educativo Visual, p. 1272.

7 ArRoYo, Marta, La recesión económica ha provocado una crisis mundial de derechos humanos, Madrid, http://www. elmundo.es/elmundo.ht/m.
} 
Brasil, México, Rusia y China, entre otros, a mejorar su historial de protección de los derechos. ${ }^{8}$

Cabe destacar que la finalidad de los derechos humanos es proteger ese derecho inherente a la persona, no importa si la persona está discapacitada o no, para que ambas puedan ejercer sus derechos, para ello los tres poderes de la nación deben unir fuerzas e invertir en las demandas que solicitan las personas discapacitadas que forman un grupo muy vulnerable en esta sociedad.

\section{El concepto de discapacidad}

En el pasado, el concepto de la discapacidad siempre ha sido negativo, primeramente se le conoció como el "modelo médico de la discapacidad", mismo que fue sustituido por el "modelo social de la discapacidad", esto debido a que en la actualidad las personas discapacitadas son vistas como un grupo vulnerable que tiene la necesidad de mayor de protección jurídica; ahora bien, el término "persona invalida" era utilizado para "designar las condiciones sociales o económicas que aquejan a las personas o a las familias vinculadas con el tema de la discapacidad", hoy en día un individuo será considerado "inválido" o "persona discapacitada" dependiendo de la actitud que tenga la sociedad hacia ellos. ${ }^{9}$

La Organización Mundial de la Salud ha establecido la diferencia conceptual de los términos deficiencia, ${ }^{10}$ discapacidad ${ }^{11}$ e invalidez ${ }^{12}$ y minusvalía, ${ }^{13}$ mismas que deben relacionarse con las posibilidades de la persona para encontrar, conservar y progresar en un trabajo, es decir, incorporarse socialmente a la vida productiva.

La Ley Federal para Personas con Discapacidad, en su artículo 10., establece que: "Persona con discapacidad será todo ser humano que presenta temporal o permanentemente una disminución en sus facultades físicas, intelectuales, o

\footnotetext{
${ }^{8}$ Idem.

${ }^{9}$ http://www.lazarum.com/2/articulos/articulos_ver.php?idarticulo=140.

${ }^{10}$ Deficiencia: se define como toda perdida o anormalidad de una estructura o función psicológica, fisiológica o anatómica.

11 Discapacidad: diferentes limitaciones funcionales de carácter temporal o permanente que se registra en la población mundial y que revisten la forma de deficiencias físicas, intelectuales o sensoriales, de una dolencia que requiera atención médica o incluso una enfermedad mental que limite la capacidad de ejercer una o más actividades esenciales de la vida diaria, que puede ser causada o agravada por el entorno económico y social.

12 Invalidez: término que designa a toda persona cuyas posibilidades de obtener, conservar y progresar en un empleo adecuado se encuentren reducidas debido a una disminución de su capacidad fisica o mental debidamente reconocida por una autoridad médica competente.

${ }_{13}$ Minusvalia: situación desventajosa para una persona determinada, como consecuencia de una deficiencia o de una discapacidad que limita o impide el desempeño de un papel social que es normal en su caso según su edad, sexo y factores sociales y culturales, $h$ ttp://www.lazarum.com/2/articulos/articulos_ver.php?idarticulo=140.
} 
sensoriales que le limitan realizar una actividad normal (fracción ו)". Ahora bien, el término discapacidad puede comprender el aspecto físico, sensorial, psiquiátrico y cognitivo; entendiéndose por incapacidades físicas aquellas que afectan los movimientos tales como la espina bífida, síndrome pospolio o parálisis cerebral. Las incapacidades sensoriales son aquellas que afectan uno o más sentidos, tales como la ceguera o la sordera; las incapacidades cognitivas como el autismo o el Síndrome de Down, y las incapacidades psiquiátricas como la depresión o la esquizofrenia. ${ }^{14}$

Por lo tanto, cuando existan dentro de la sociedad personas con alguna discapacidad física se adoptarán medidas encaminadas a impedir que se produzcan deficiencias físicas, intelectuales, mentales y sensoriales (fracción ı), y se someterán a un proceso de rehabilitación cuyo objetivo va encaminado a permitir que una persona con discapacidad alcance un nivel físico, mental, sensorial o social óptimo, que permita compensar la pérdida de una función, así como para facilitar el reajuste de orden social (fracción וㅣ). Las personas con discapacidad tienden a necesitar de estimulación temprana, ${ }^{15}$ igualdad de oportunidades, ${ }^{16}$ asistencia social, ${ }^{17}$ apoyo técnico, ${ }^{18}$ necesidad educativa especial, ${ }^{19}$ trabajo protegido, ${ }^{20}$ servicios de apoyo ${ }^{21}$ y organizaciones para personas con discapacidad ${ }^{22}$ (fraccio-

\footnotetext{
14 Idem.

${ }^{15}$ Atención brindada al niño entre 0 y 7 años para potenciar y desarrollar al máximo sus posibilidades físicas, intelectuales, sensoriales y afectivas mediante programas sistemáticos y secuenciados que abarcan todas las áreas del desarrollo humano, sin forzar el curso lógico de la maduración.

${ }^{16}$ Principio que reconoce la importancia de las diversas necesidades del individuo, las cuales deben constituir la base de la planificación de la sociedad con el fin de asegurar el empleo de los recursos para garantizar que las personas disfruten de iguales oportunidades de acceso y participación en idénticas circunstancias.

17 Se entiende por asistencia social, al conjunto de acciones tendientes a modificar y mejorar las circunstancias de carácter social que impidan al individuo su desarrollo integral, asi como la protección física, mental y social de personas en estado de necesidad, desprotección o desventaja fisica o mental, hasta lograr su incorporación a una vida plena y productiva.

${ }^{18}$ Ayudas técnicas: son aquellos dispositivos tecnológicos que permiten recuperar, rehabilitar o compensar una o más limitaciones funcionales motrices, sensoriales, intelectuales o emocionales de la persona con discapacidad, con el propósito de impedir su progresión o derivación en otra discapacidad; consecuentemente se podrán eliminar o reducir los obstáculos físicos y de comunicación y de posibilitar su plena integración en condiciones de una mayor normalidad.

${ }^{19}$ Es un conjunto de servicios, programas y recursos educativos puestos a disposición de las personas para favorecer su desarrollo integral, facilitándoles la adquisición de habilidades y destrezas que les capaciten para lograr el fin último de la educación.

${ }^{20}$ Aquel que realizan las personas con discapacidad intelectual o de cualquier otro tipo y que no pueden ser incorporadas al trabajo común por no alcanzar a cubrir los requerimientos de productividad.

${ }^{21}$ Son aquellas ayudas técnicas, equipo, recursos auxiliares, asistencia personal y servicios de educación especial requeridos, para aumentar su grado de autonomía y garantizar oportunidades equiparables de acceso al desarrollo. 22 Todas aquellas figuras asociativas constituidas legalmente para salvaguardar los derechos de las personas con discapacidad y que buscan facilitar la participación de las personas en las decisiones relacionadas con el diseño, aplicación y evaluación de programas para el desarrollo e integración social. http://www.cddhcu.gob.mx/comisiones/ discapacitados/htm/s/marjur/.
} 
nes IV, V, VI, XVII, IX, Xl, XII, XIII, XIV de la Ley General de Protección a Personas con Discapacidad).

\section{Marco jurídico regulatorio de los derechos de las personas con discapacidad}

México cuenta con un marco jurídico federal que protege a las personas con alguna discapacidad física, tales como la Ley General de Protección a Personas con Discapacidad, la Norma Oficial Mexicana para la Atención Integral a Personas con Discapacidad, Ley de Protección e Integración de las Personas Discapacitadas, Convenio 159 sobre la Readaptación Profesional y el Empleo de Personas lnválidas de la Organización Internacional del Trabajo, Convención Interamericana para la Eliminación de Todas las Formas de Discriminación Contra las Personas con Discapacidad, así como también se cuenta con un Instituto Nacional de las Personas con Discapacidad. ${ }^{23}$

En México la Convención sobre los Derechos de las Personas con Discapacidad fue aprobado por el Senado de la República el 27 de septiembre de 2007, así como su protocolo facultativo e instrumentos adoptados por la Asamblea General de la Organización de las Naciones Unidas (onU) fue denominado el primer tratado de derechos humanos del siglo xxı, señalado así por el presidente de la Comisión de Atención a Grupos Vulnerables, el panista Guillermo Tamborrel; la finalidad de dicha Convención es proteger y asegurar el pleno goce, en condiciones de igualdad, de todos los derechos humanos de las personas con discapacidad, en un contexto de respeto a su dignidad.

La Constitución mexicana, en su artículo 4, establece la garantía de igualdad, especifica que el hombre y la mujer serán iguales ante la ley, pero también establece que "Toda persona tiene derecho a la protección de la salud [...]”, así como que "toda persona tiene derecho a un ambiente adecuado para su desarrollo [...]", ${ }^{24}$ es en esta parte donde se integrarían las personas con alguna discapacidad física, pues si bien es cierto que la Constitución no habla específicamente de ellas, podemos utilizar la garantía de igualdad para encuadrarlas.

En el artículo 123 constitucional, que establece las bases de la seguridad social, se encuentran las bases del derecho de la asistencia social, que se encarga de asistir socialmente y reintegrar e integrar a las personas, que por sus condiciones físicas, mentales, jurídicas o sociales requieran de servicios especializados para su protección y pleno desarrollo.

\footnotetext{
${ }^{23}$ Fracciones XXV, XXVI, XXVII, XXVIII, XIX de la Ley Federal para Personas con Discapacidad.

${ }^{24}$ Constitución Política de los Estados Unidos Mexicanos.
} 
La Ley General de Protección a Personas con Discapacidad es una ley reglamentaria del párrafo 3 del artículo 10. de la Constitución Política de los Estados Unidos Mexicanos, promulgada el 10 de junio de 2005, y que corresponde a las dependencias de la administración pública federal, entidades paraestatales, órganos desconcentrados y al Consejo Nacional para las Personas con Discapacidad su aplicación. El objeto de esta ley es:

[...] establecer las bases, fundamentos y condiciones que permitan obtener la plena inclusión social de las personas con discapacidad en un marco de igualdad y equiparación de oportunidades, particularmente en ámbitos relacionados con la prevención, salud, su incorporación a los diferentes regímenes de educación, capacitación, trabajo y seguridad social; la participación en actividades culturales, deportivas, recreativas y el desarrollo social; así como velar por el goce y ejercicio de los derechos, deberes y garantías que la Constitución Política de los Estados Unidos Mexicanos, los tratados internacionales, las leyes federales, los reglamentos (artículo 2o.).

Los beneficios de esta ley son para todas las personas con discapacidad, nacionales o extranjeros, y se buscará la protección de los acuerdos internacionales para los conciudadanos que se encuentren fuera del país (artículo 3).

La Ley de Asistencia Social, aprobada por el Congreso de la Unión el 2 de septiembre de 2004, tiene por objeto proteger intereses y derechos de personas con capacidades diferentes, estableciendo los servicios de asistencia social y las instituciones de asistencia, la rehabilitación e integración a la vida productiva o activa de personas con algún tipo de discapacidad. Se entenderá a la asistencia social como la atención a personas que por sus características requieran de apoyos básicos de subsistencia y desarrollo.

Los ordenamientos jurídicos que se han reformado en el país de 1992 a 1999 son: el Código Civil para el Distrito Federal en Materia Común y para toda la República en Materia Federal; Código Civil de Procedimientos Civiles para el Distrito Federal; Ley del Seguro Social; Ley General de Educación; Código Federal de Instituciones y Procedimientos Electorales; Ley General de Asentamientos Humanos; Ley de Adquisiciones y Obras Públicas; Ley de Aeropuertos; Ley de Aviación Civil; Ley Federal de Protección al Consumidor; Ley Reglamentaria de Servicios Ferroviarios; Ley General de Bibliotecas; Ley Federal de Estímulo y Fomento al Deporte; Ley Aduanera; Código Penal para el Distrito Federal en Materia Común y para toda la República en Materia del Fuero Federal.

En el Distrito Federal, de 1995 a 1999, se reformaron la Ley del Medio Ambiente; Ley de Desarrollo Urbano; Ley para el Funcionamiento de Establecimientos Mercantiles; Ley de Fomento Económico; Ley para la Celebración de 
Espectáculos Públicos; Ley de Salud; Ley de Transporte, y la Ley del Deporte. En marzo de 1999 se firmó el Convenio para la Defensa de los Derechos de las Personas con Discapacidad por parte de la Procuraduría Federal del Consumidor y el Sistema para el Desarrollo Integral de la Familia.

En esta misma forma, la mayoría de los estados cuenta con legislación de carácter estatal ${ }^{25}$ para la protección de la discapacidad, aunque Guerrero, Hidalgo, Querétaro, Quintana Roo, Sonora y Veracruz cuentan con Proyecto de Ley. Los estados que cuentan con leyes para la discapacidad son:

- Aguascalientes: Ley de Integración Social de Personas con Discapacidad.

- Baja California: Ley para Incorporar al Desarrollo Productivo de la Sociedad a Discapacitados "Prof. Álvaro Mateos Núñez".

- Baja California Sur: Ley para la Integración Social de Discapacitados.

- Campeche: Ley de Protección a Minusválidos y Senescentes.

- Coahuila: Ley para el Desarrollo Integral de las Personas con Discapacidad.

- Colima: Ley para la Protección de los Discapacitados y Ancianos.

- Chiapas: Ley para Personas con Discapacidad.

- Chihuahua: Ley para las Personas con Discapacidad.

- Distrito Federal: Ley para las Personas con Discapacidad.

- Durango: Ley Durango para la Protección de las Personas con Deficiencia Mental.

- Estado de México: Ley para la Protección e Integración al Desarrollo de las Personas con Discapacidad.

- Guanajuato: Ley de Asistencia para Discapacitados.

- Jalisco: Código de Asistencia Social (libro v).

- Michoacán: Ley para la Protección e Integración de las Personas Discapacitadas.

- Morelos: Ley de Atención Integral para Personas con Discapacidad.

- Nayarit: Ley de Integración Social de Personas con Discapacidad.

- Nuevo León: Ley de Integración Social de Discapacitados.

- Oaxaca: Ley de Protección a Discapacitados y Senescentes.

- Puebla: Ley de Integración Social de Personas con Discapacidad.

- San Luis Potosí: Ley de Integración Social de Personas con Discapacidad.

- Sinaloa: Ley de Protección e Integración Social de Personas con Discapacidad y Senescentes.

- Tabasco: Ley para la Protección y Desarrollo de los Discapacitados.

- Tamaulipas: Ley de Integración Social de Personas con Discapacidad.

${ }_{25}$ http://www.cddhcu.gob.mx/comisiones/discapacitados/htm/s/marjur/. 
- Tlaxcala: Ley de Integración Social para Personas con Discapacidad.

- Yucatán: Ley para la Investigación de Personas con Discapacidad.

- Zacatecas: Ley Estatal para la Incorporación al Desarrollo Social de las Personas con Discapacidad.

\section{Conclusión}

Tenemos que admitir que culturalmente no estamos preparados para la protección de este grupo tan vulnerable como lo son las personas discapacitadas, es obvio que no se ha dado cumplimiento a las leyes vigentes que garantizan sus derechos, por lo que es importante crear una conciencia de respeto e inclusión para estas personas. En las instituciones educativas se debe formar en los educandos una conciencia de justicia y respeto para las personas discapacitadas, que lejos de ser diferentes son una parte importante de la sociedad. Es justo crear medios laborales justos y bien remunerados, con seguridad social, que permita su libre ejercicio de profesión, tal como lo marca la Constitución. Es importante pensar en la urbanización y establecimiento de instrumentos tecnológicos y técnicos en la vía pública cómodos, seguros y dignos, que les permita su inclusión en los ámbitos familiares y sociales que tanto los margina.

\section{Bibliografía}

Álvarez Mendiola, G., Sistema educativo nacional de México, México, Secretaría de Educación Pública-Organización de Estados lberoamericanos, 1994.

Arroyo, Marta, La recesión económica ha provocado una crisis mundial de derechos humanos, Madrid, http://www.elmundo.es/elmundo.html.

Barnach-Calbó, E., "La nueva educación indígena en lberoamérica", Revista Iberoamericana de Educación, 1997.

124 Buergenthal, Thomas, Derechos humanos internacionales, 2a. ed., México, Gernika, 1996.

Bonfil Batalla, G., Pensar nuestra cultura. Ensayos, Alianza, 1998.

Cálvez Ruiz, X., "El futuro de los pueblos indígenas”, Gaceta Universidad (Benemérita Universidad Autónoma de Puebla), 2001.

Carpizo, Jorge, "Los derechos humanos”, en Soberanes, José Luis (comp.), Tendencias actuales del derecho, 2a. ed., disponible en http://www.bibliojuridi ca.org/libros/3/1376/27.pdf. 
Díaz-Couder, E., "Diversidad cultural y educación en lberoamérica”, Revista Iberoamericana de Educación, 1998.

Didier, J., Diccionario de filosofía, México, Diana, 2002.

Durand Alcántara, C. y González Gómez, G., Premisas sociojurídicas del desarrollo de los pueblos indios. Etnicidad y derechos humanos. Mesoamérica, crítica jurídica, México, unam, Instituto de Investigaciones Jurídicas, 1993.

Enciclopedia Salvat, México, Salvat Mexicana de Ediciones, 1983.

Lastra, Y., "Los hilos del lenguaje", conferencia impartida en el foro de las Lenguas indígenas, Benemérita Universidad Autónoma de Puebla, 2008.

Mendieta y Núñez Lucio, El derecho social, México, 1967.

Ordóñez Cifuentes, J. E. y Ordóñez Mazariegos, C. S., Etnicidad y derechos humanos. Mesoamérica: Crítica Jurídica, México, unam, Instituto de Investigaciones Jurídicas, 1993.

Ordóñez-Mazariegos, C. S., Derechos humanos de los pueblos indios, etnicidad $y$ derecho: un diálogo postergado entre los cientificos sociales, México, Cuadernos-unam, 1996.

Palacios-Alcocer, M., El régimen de las garantías sociales en el constitucionalismo mexicano, México, unam, 1995.

Rabasa, E. y Caballero, G., Mexicano ésta es tu Constitución, México, Miguel Ángel Porrúa, 1997.

Schemelkes, S., "México educación intercultural bilingüe destinada a los pueblos indígenas", Foro virtual-Educación para la interculturlidad, migración, desplazamiento y derechos lingüísticos, Foro Latinoamericano de Políticas Educativas, 2008.

Stavenhagen, R., Aspectos nacionales e internacionales sobre derecho indígena, UNAM, Instituto de Investigaciones Jurídicas, 1991.

Stavenhagen, R., “¿Asimilación o pluralismo? Identidad indígena y multiculturalismo en América Latina”, Desarrollo y cooperación, 2001.

Trueba Urbina, Alberto, Derecho social mexicano, México, 1978. 